\title{
Managing Patient Populations in Primary Care: Points of Leverage
}

\author{
Robert Eidus, MD, MBA, Wilson D. Pace, MD, and Elizabeth W. Staton, MSTC
}

Common "quality" metrics may represent the quality of care for large populations; however, they do not adequately represent quality in individual primary care settings, especially as stand-alone indices. Using discreet threshold values to measure quality in primary care may result in physicians focusing on managing patients by the numbers at the expense of making individualized and nuanced clinical decisions. Current performance measures may be misapplied as proxies for both cost savings and quality. We posit that developing and focusing measurement on high-leverage activities will yield better clinical outcomes and potentially lower cost. As a starting point for further work in this area, we suggest the development of metrics that track identification and management of depression; management of transitions of care; care coordination; team-based care; identification and support of socially frail/isolated individuals; pharmacologic management, including optimizing medication and dealing with adherence issues; and establishment of a therapeutic environment. These processes, or others like them, will require infrastructure that may be costly and time-consuming, and measuring these processes will require thought and effort. Nevertheless, we believe developing metrics based on high-leverage activities will yield greater clinical and economic returns than relying on the metrics currently in place. ( $\mathrm{J}$ Am Board Fam Med 2012;25:238-244.)

Keywords: Delivery of Health Care, Health Care Economics, Health Policy, Quality of Health Care

"Not everything that can be counted counts, and not everything that counts can be counted." - Albert Einstein (1879-1955)

Mary Smith, 64 years old with well-controlled diabetes, takes metformin and a statin at the lowest dose and has no additional risk factors. She exercises regularly, has strong social and family support systems, and has low copays for primary care visits and medications. Mrs. Smith monitors her blood pressure and blood glucose regularly without any assistance. At her biannual visit with her primary care clinician, which takes 15 minutes, her blood pressure was $128 / 78 \mathrm{~mm} \mathrm{Hg}$, and her blood work

This article was externally peer reviewed.

Submitted 23 September 2010; revised 5 May 2011; accepted 16 May 2011.

From the Cranford Family Practice, Cranford, NJ (RE); and the Department of Family Medicine, University of Colorado School of Medicine, Aurora, CO (WDP, EWS).

Funding: none.

Conflict of interest: none declared.

Corresponding author: Robert Eidus, MD, MBA, $123 \mathrm{~N}$. Union Ave., Suite 204, Cranford, NJ 07016 (E-mail: bobeidus@eidushealth.com). revealed a glycosylated hemoglobin (HbA1c) level of 6.9 and a low-density lipoprotein cholesterol of 98 .

Betty Jones, 64 years old with diabetes, has neither a good understanding of her illnesses nor the knowledge to control it. She is taking 8 prescribed medications, is a smoker, and has hypertension, hyperlipidemia, and arthritis. Her financial status is shaky, but because her doctor's office has arranged transportation with the local paratransit agency, she does come in regularly for appointments. She sees not only the physician, she also regularly sees the nurse health educator and the patient navigator and has frequent consultations with the pharmacist. Each visit takes at least 30 minutes. At the time of her most recent visit, her blood pressure was 130/ 64, her low-density lipoprotein cholesterol was 101, and her HbAlc was 7.2.

\section{The Power of Data}

The clinicians caring for both Mary and Betty record data about them for accreditation, recognition, and pay-for-performance incentive programs, 
as well as insurance rating programs. Mary's performance passes all criteria despite the fact that the practice has little influence on those outcomes. Meanwhile, Betty underperforms on all measures, even though she is a much more complex patient on whom the practice has expended much more effort to help her achieve the current results. Although one could argue which of these patients' data better represent her provider's care, focusing too narrowly on these data raises concerns that are far more pressing. The first of these concerns is whether physicians will become so attunedthrough incentives and report cards-to managing by the numbers that they no longer make individualized and nuanced clinical decisions.

Recent articles in the British Medical fournal ${ }^{1}$ and Fournal of the American Medical Association ${ }^{2,3}$ demonstrate the pitfalls of using discreet threshold values to measure quality in primary care. Although such measures have value in representing quality of care for large populations over a long period of time, they do not properly assess quality in individual primary care settings, especially as stand-alone indices. Furthermore, slight deviations from the ideal levels of these measurements are unlikely to have clinical significance. For example, it is unlikely that a blood pressure of $130 / 64 \mathrm{~mm} \mathrm{Hg}$ results in any worse outcome than a blood pressure of 128/78 $\mathrm{mm} \mathrm{Hg}$. Furthermore, focusing too much on lowering particular measurements may not result in good long-term outcomes for patients. For instance, aggressive lowering of HbA1c and blood pressure may be doing more harm than good, at least in selected patients. ${ }^{4-6}$ Managing by the numbers needs to be tempered by individual patient considerations and is limited by the current state of evidence for or against specific numbers.

In addition to the concern of the behaviors of physicians managing individual patients, there is also a concern of the misapplication of these performance measures as proxies for both cost savings and quality. Many pilot patient-centered medical home projects are emphasizing intermediate clinical outcomes as quality indicators (Allyson Gottsman, Health Teamworks, personal communication). By using these measures, payers are creating an environment in which clinicians and others become captive to that which is measurable as opposed to that which is meaningful. What is measured is what gets paid for, so offices create an infrastructure to be a "high performer" on the limited set of measures rather than creating structures and processes around high leverage activities. ${ }^{7-9}$ Although there is a current emphasis on measuring intermediate outcomes, it might serve us better if we focused on measuring high-value processes.

\section{A Better Alternative: High-Leverage Activities}

High-leverage activities may be a better focus for measuring quality. High-leverage structures and processes are those that greatly influence clinical and economic outcomes in both the short- and long-term. For example, a high-impact activity might be addressing a patient's adherence problems with her blood pressure medications and adjusting therapy to overcome these issues. ${ }^{10}$ Meanwhile, a low-leverage activity (which coincidentally is a "high performer" activity according to many metrics) is having practice staff call ophthalmologists' offices to obtain eye examination reports to be able to score better on the completion of eye examinations. It is not that such low-leverage activities have no value, but staff and resources might be better allocated to high-leverage activities.

Based on our experience and supporting literature, we propose several high-leverage activities that may yield better outcomes and lower cost, and thus should be a focus for research toward the development of quality metrics. A starter set of high-leverage activities might include (1) the identification and management of depression; (2) management of transitions of care; (3) care coordination; (4) team-based care; (5) the identification and support of the socially frail/ isolated individual; (6) pharmacologic management, including optimizing medication and dealing with adherence issues; and (7) establishing a therapeutic environment.

We propose that developing measurements for these activities or other similar activities—-thereby making it possible to provide incentives for them-is a worthy goal. The high-leverage activities we propose are more difficult to measure than blood pressure or eye examination reports, but, over time, focusing on them is likely to have a greater impact on health across all patients in a practice. As metrics are developed, they can be used to advance research into the effectiveness of the care processes and further refine, expand, or narrow this list of highleverage processes. 


\section{Identification and Management of Depression Why Is It High Leverage?}

Depression has been well established as a comorbidity and contributing factor to other chronic illnesses. ${ }^{11-13}$ People with depression have more somatic complaints, which may lead to unnecessary diagnostic or treatment services. Depression, as a comorbidity to other chronic illnesses, generally doubles the cost of care while frequently worsening survival for that chronic illness. ${ }^{14,15}$

\section{Infrastructure and Processes Needed}

Identification of depression via screening is recommended if there is an associated process to care for those who are identified. ${ }^{16}$ Screening can be accomplished through 2 questions. ${ }^{17,18}$ Clinicians can use the 9-item Patient Health Questionnaire to monitor patients with depression in terms of their response to treatment. Guidelines are well established for management and treatment decisions linked to the 9-item Patient Health Questionnaire scores and trends. Psychologists, psychiatrists, and social workers can be used as part of the care team either by directly engaging the patient in treatment or by participating in team management conferences. ${ }^{16,19}$ Tracking systems and medication compliance monitoring systems can further enhance care and outcomes. ${ }^{20-22}$ At least one state has instituted depression treatment outcomes as a quality metric, demonstrating that it is possible. ${ }^{23}$

\section{Management of Transitions of Care Why Is It High Leverage?}

Numerous studies have shown that transitions of care represent situations at high risk for lack of continuity of care and information. ${ }^{24-26}$ Boult et $\mathrm{al}^{27}$ have shown that focusing on care transition can reduce the incidence of hospitalization/rehospitalization. Patients entering or exiting an acute care facility have the most urgent needs related to care coordination. Breakdown in coordination at admission to an acute care facility can lead to unnecessary tests and procedures, medication errors, and prolonged stays. Care transition issues also occur between ambulatory care and emergency departments, between primary care and specialist care, and when patients enter and exit long-term care and mental health facilities. ${ }^{28-30}$

\section{Infrastructure and Processes Needed}

Processes are needed to identify quickly the providers and information that are important in relation to a patient's current care. For example, emergency department personnel need effective processes for identifying the primary care physician, other relevant care providers, and important clinical data at the time of assessment. Once patients are discharged, hospitalists need processes to determine which clinicians will be providing outpatient care. Ambulatory clinicians must be informed of what happened during an admission and what requires attention after discharge. This process is supported with timely, accurate, and thorough discharge summaries but may require contact between inpatient and ambulatory providers. Primary care physicians need to be able to receive and implement a complete and timely handoff, which may include, among other things, a house call just after discharge from the hospital. Interfaces between hospitals and primary care providers through regional health information exchanges provide a technical platform for these activities but are not substitutes for good processes.

\section{Care Coordination}

\section{Why Is It High Leverage?}

Patients with multiple chronic illnesses are at high risk for fragmentation of care, which leads to missed appointments, redundant tests, adverse drug events, problems with patient adherence, and many other undesirable events. ${ }^{31}$ Seamless, timely, and complete exchange of information among treating providers is needed. ${ }^{32}$ Patients also need help navigating a complex maze of providers and health systems. Furthermore, there needs to be a process of outreach to patients with chronic illnesses who have remained outside the care environment. Large-scale medical home projects in North Carolina (Community Care of North Carolina) and at Geisinger Health System have utilized care coordinators extensively and have realized both cost savings and improvements in care. ${ }^{33,34}$

\section{Infrastructure and Processes Needed}

The major technological platform is the disease registry, which ideally can identify patients at risk, both those who are receiving care and those who are not. Processes are needed to identify patients who need navigation and coordination of their care. Systems that ensure pertinent information flows 
with the patient will help to minimize pitfalls and errors related to poor care coordination. Dedicated, trained staff at the primary care site are needed to make use of the data, to interact with patients both on- and off-site, and to act as a conduit of information between the patients and the care staff.

\section{Team-based Care \\ Why Is It High Leverage?}

Team-based care is one of the centerpieces of the chronic care model described by Wagner et al. ${ }^{35}$ The model recognizes that the physician cannot do it all and that there are patient needs that cannot be met in a physician-centric system. Health care has become increasingly complex for the patient as well as for those providing care. Organizations such as Geisinger Health System, Kaiser Permanente, and Virginia Mason Medical Center have used this model widely and have been able to demonstrate positive outcomes. ${ }^{36-38}$

\section{Infrastructure and Processes Needed}

One must be able to identify patients who are most in need of team-based care. These include patients with multiple chronic illnesses who take multiple medications, who have social service needs, who have difficulty in attending appointments, and who are heavy utilizers. The composition of care teams may vary widely depending on local resources available. Some practices have created virtual care teams by closely aligning their practices with organizations in their local community, such as social service organizations and pharmacies. Among the most common members of team-based care are nurses, nurse practitioners, pharmacists, social workers, and psychologists. Team-based care requires a coordinated process of team interaction, beginning with identification of patients in need and including a longitudinal process of care planning and outcomes tracking.

\section{Identification of the Socially Frail Individual Why Is It High Leverage?}

Attributes such as social isolation and low selfesteem are important predictors of poor clinical outcomes in adolescents, pregnant women, elderly patients, and people with multiple chronic illnesses. $^{36,37}$ Although low self-esteem and social isolation may be important predictors of and coex- ist with depression, they also exist independently. The socially frail individual can be easily identified and tracked. ${ }^{39}$ There is evidence that timely lowcost intervention strategies can move these patients to a more normalized risk profile. ${ }^{40,41}$

\section{Infrastructure and Processes Needed}

A system to identify patients at risk can be implemented using virtually any member of the care team. Only a few questions are usually necessary. Once identified, processes are needed for regular outreach to these socially frail individuals, as well as linkage to community social service resources, mental health services, paraprofessionals, lay volunteers, and patients' existing social support networks. When the patient is in the primary care office, there needs to be a process of reassessment of the patient's social frailty index as well as care for any underlying mental health conditions.

\section{Pharmacologic Management Why Is It High Leverage?}

Many conditions that in the past were treated surgically or not at all are now treated with medication. Medication adherence is causally related to better outcomes and lower health care costs, ${ }^{42}$ yet the increased use of medications has caused increased adverse drug events, drug-drug interactions, affordability issues, nonadherence, and patient confusion about how to properly take medications. The World Health Organization predicts that improvements in medication adherence will have a far greater effect on the health of populations than improvements in specific medical treatments. ${ }^{10}$ Several health systems have employed systematic processes to address pharmacologic management. Geisinger Health System and Group Health Cooperative have made adherence a priority and address the issue through multidimensional approaches. ${ }^{43}$ Some systems use onsite consulting pharmacists. ${ }^{36,37}$

\section{Infrastructure and Processes Needed}

Electronic systems can be utilized to identify drugdrug and drug-disease interactions as well as to link to the insurance companies' formularies to save the patient money. Systems can be implemented using community-wide data or via clearinghouses to identify all medications prescribed to the patient regardless of the prescriber or the pharmacy. Sys- 
tems are also available to detect medication persistence concerns. Linkage to low- or no-cost medications for patients can be essential for certain populations. Primary care medication reconciliation, including having a team member review with the patient their medications, what they are for, how to take them, and potential side effects, often improves the effectiveness of medications prescribed. ${ }^{36,37}$ Pharmacists can be a member of the team either onsite or as a remote consultant. ${ }^{36,37,43}$

\section{Establishment of the Therapeutic Environment Why Is It High Leverage?}

The importance of the therapeutic relationship goes back well beyond the advent of modern medicine and transcends traditional Western medicine. Despite the technological advances and the increased numbers of people who now participate in a patient's care, patients still value a friendly care team that knows them, as well as a clinician who takes the time to listen to and understand them as individuals. ${ }^{44}$ The duration of the relationship with a practitioner and the frequency with which a patient sees an individual practitioner has a direct correlation with positive outcomes. ${ }^{45,46}$

\section{Infrastructure and Processes Needed}

Maintaining a therapeutic relationship should be a central component of the medical home even as practices morph into larger organizations and have more team members involved in a patient's care. Systems need to make large organizations seem small to the patient, with a consistent care team, from receptionist to physician. Team-based care does not mean that members of the team are interchangeable or that we should not foster longitudinal relationships, especially between the patient and the physician. Good charting and good communication among providers are no substitute for a longitudinal relationship in fostering a therapeutic environment.

\section{Implications of High-Leverage Activities in the Development of the Patient-Centered Medical Home Infrastructure}

Few traditional practices and only slightly more National Committee for Quality Assurance-recognized patient-centered practices have implemented the infrastructure and processes described in this article. Few provider organizations have all these processes in place and working well. Most of these activities are costly and can be time consuming to build. Furthermore, the incentives given to practices are not to build these processes and infrastructures but to attain good scores on a limited set of outcome indicators. Insurance companies are hoping for A (lower costs and better outcomes) but are providing incentives for B (tracking down eye examination reports). ${ }^{47}$

We can continue on our current path. If so, provider organizations will be prey to cherry picking (Mary Smith) and lemon dropping (Betty Jones), and we will spend a lot of energy with limited gains. ${ }^{48}$ On the other hand, we can learn from the successes of organizations that have implemented high-leverage processes and build the necessary infrastructure, processes, and metrics to incent these behaviors. As we measure, refine, and improve these processes we may achieve clinical and economic outcomes that currently can only be dreamed of.

\section{References}

1. Heath I, Rubinstein A, Stange KC, van Driel ML. Quality in primary health care: a multidimensional approach to complexity. BMJ 2009;338:b1242.

2. Nyweide DJ, Weeks WB, Gottlieb DJ, Casalino LP, Fisher ES. Relationship of primary care physicians' patient caseload with measurement of quality and cost performance. JAMA 2009;302:2444-50.

3. Berwick DM. Measuring physicians' quality and performance: adrift on Lake Wobegon. JAMA 2009; 302:2485-6.

4. Dluhy RG, McMahon GT. Intensive Glycemic Control in the ACCORD and ADVANCE Trials. N Engl J Med 2008;358:2630-3.

5. Gerstein HC, Miller ME, Byington RP, et al. Effects of intensive glucose lowering in type 2 diabetes. N Engl J Med 2008;358:2545-59.

6. ADVANCE Collaborative Group, Patel A, MacMahon $\mathrm{S}$, et al. Intensive blood glucose control and vascular outcomes in patients with type 2 diabetes. N Engl J Med 2008;358:2560-72.

7. Campbell SM, Reeves D, Kontopantelis E, Sibbald B, Roland M. Effects of pay for performance on the quality of primary care in England. N Engl J Med 2009;361:368-78.

8. Fleetcroft R, Cookson R. Do the incentive payments in the new NHS contract for primary care reflect likely population health gains? J Health Serv Res Policy 2006;11:27-31. 
9. Holmboe E, Kim N, Cohen S, et al. Primary care physicians, office-based practice, and the meaning of quality improvement. Am J Med 2005;118:917-22.

10. World Health Organization, Sabaté E. Adherence to long-term therapies: evidence for action. Geneva: World Health Organization; 2003.

11. Piette JD, Richardson C, Valenstein M. Addressing the needs of patients with multiple chronic illnesses: the case of diabetes and depression. Am J Manag Care 2004;10(2 Pt 2):152-62.

12. Golden SH, Lazo M, Carnethon M, et al. Examining a bidirectional association between depressive symptoms and diabetes. JAMA 2008;299:2751-9.

13. Noel PH, Williams JW Jr, Unutzer J, et al. Depression and comorbid illness in elderly primary care patients: impact on multiple domains of health status and well-being. Ann Fam Med 2004;2:555-62.

14. Unutzer J, Schoenbaum M, Katon WJ, et al. Healthcare costs associated with depression in medically Ill fee-for-service medicare participants. J Am Geriatr Soc 2009;57:506-10.

15. Kalsekar ID, Madhavan SM, Amonkar MM, et al. The effect of depression on health care utilization and costs in patients with type 2 diabetes. Manag Care Interface 2006;19:39-46.

16. Screening for depression in adults: U.S. preventive services task force recommendation statement. Ann Intern Med 2009;151:784-92.

17. Corson K, Gerrity MS, Dobscha SK. Screening for depression and suicidality in a VA primary care setting: 2 items are better than 1 item. Am J Manag Care2004 2004;10(11 Pt 2):839-45.

18. Kroenke K, Spitzer RL, Williams JBW. The patient health questionnaire-2: Validity of a two-item depression screener. Med Care 2003;41:1284-92.

19. Task Force on Community Preventive Services, Guide to Community Preventive Services. Mental health \& mental illness: collaborative care for the management of depressive disorders. Atlanta, GA: Centers for Disease Control and Prevention; 2003. Available at: www.thecommunityguide.org/mental health/collab-care.html. Accessed May 3, 2011.

20. Peters AL, Davidson MB. Application of a diabetes managed care program. The feasibility of using nurses and a computer system to provide effective care. Diabetes Care 1998;21:1037-43.

21. Bordley WC, Margolis PA, Stuart J, Lannon C, Keyes L. Improving preventive service delivery through office systems. Pediatrics 2001;108:E41.

22. Renders CM, Valk GD, Griffin S, Wagner EH, Eijk JT, Assendelft WJ. Interventions to improve the management of diabetes mellitus in primary care, outpatient and community settings. Cochrane Database Syst Rev 2001;(1):CD001481.

23. Institute for Clinical Systems Improvement. The DIAMOND Initiative: depression improvement across Minnesota, offering a new direction. Bloom- ington, MN: Institute for Clinical Systems Improvement; 2008.

24. Nagpal K, Arora S, Abboudi M, et al. Postoperative handover: problems, pitfalls, and prevention of error. Ann Surg 2010;252:171-6.

25. Petersen LA, Brennan TA, O’Neil AC, Cook EF, Lee TH. Does housestaff discontinuity of care increase the risk for preventable adverse events? Ann Intern Med 1994;121:866-72.

26. Forster AJ, Murff HJ, Peterson JF, Gandhi TK, Bates DW. The incidence and severity of adverse events affecting patients after discharge from the hospital. Ann Intern Med 2003;138:161-7.

27. Boult C, Reider L, Frey K, et al. Early effects of "Guided Care" on the quality of health care for multimorbid older persons: a cluster-randomized controlled trial. J Gerontol A Biol Sci Med Sci 2008; 63:321-7.

28. West D, Pace WD, Dickinson LM, et al. Relationship between patient harm and reported medical errors in primary care: a report from the ASIPS Collaborative. Advances in Patient Safety 2. Rockville, MD: Agency for Healthcare Research and Quality; 2008.

29. Fernald DH, Pace WD, Harris DM, West DR, Main DS, Westfall JM. Event reporting to a primary care patient safety reporting system: a report from the ASIPS collaborative [see comment]. Ann Fam Med 2004;2:327-32.

30. Kripalani S, LeFevre F, Phillips CO, Williams MV, Basaviah $\mathrm{P}$, Baker DW. Deficits in communication and information transfer between hospital-based and primary care physicians: implications for patient safety and continuity of care. JAMA 2007;297:831-41.

31. Liu CW, Einstadter D, Cebul RD. Care fragmentation and emergency department use among complex patients with diabetes. Am J Manag Care 2010;16(6): 413-20.

32. Zweifler J. The missing link: improving quality with a chronic disease management intervention for the primary care office. Ann Fam Med 2007;5:453-6.

33. Kaiser Commission on Medicaid and the Uninsured. Community care of North Carolina: putting health reform ideas into practice in Medicaid (Publication 7899). Updated May 12, 2009. Available at: http:// www.kff.org/medicaid/7899.cfm. Accessed May 3, 2011.

34. Paulus RA, Davis K, Steele GD. Continuous innovation in health care: implications of the Geisinger experience. Health Aff (Millwood) 2008;27: $1235-45$.

35. Wagner EH, Austin BT, Von Korff M. Organizing care for patients with chronic illness. Milbank Quarterly 1996;74:511-44.

36. McGinnis BD, Olson KL, Delate TM, Stolcpart RS. Statin adherence and mortality in patients enrolled in a secondary prevention program. Am J Manag Care 2009;15:689-95. 
37. Rothman RL, Malone R, Bryant B, et al. A randomized trial of a primary care-based disease management program to improve cardiovascular risk factors and glycated hemoglobin levels in patients with diabetes. Am J Med 2005;118:276-84.

38. Merenich JA, Olson KL, Delate T, Rasmussen J, Helling DK, Ward DG. Mortality reduction benefits of a comprehensive cardiac care program for patients with occlusive coronary artery disease. Pharmacotherapy 2007;27:1370-8.

39. Sluzki CE. Personal social networks and health: conceptual and clinical implications of their reciprocal impact. Fam Syst Health 2010;28:1-18.

40. Shaw E, Levitt C, Wong S, Kaczorowski J. Systematic review of the literature on postpartum care: effectiveness of postpartum support to improve maternal parenting, mental health, quality of life, and physical health. Birth 2006;33:210-20.

41. Saxena S, Misra T, Car J, Netuveli G, Smith R, Majeed A. Systematic review of primary healthcare interventions to improve diabetes outcomes in $\mathrm{mi}$ nority ethnic groups. J Ambul Care Manage 2007; 30:218-30.
42. Roebuck MC, Liberman JN, Gemmill-Toyama M, Brennan TA. Medication adherence leads to lower health care use and costs despite increased drug spending. Health Aff (Millwood) 2011;30:91-9.

43. Cutler DM, Everett W. Thinking outside the pillbox-medication adherence as a priority for health care reform. N Engl J Med 2010;362:1553-5.

44. Safran DG. Defining the future of primary care: what can we learn from patients? Ann Intern Med 2003;138:248-55.

45. Scott JG, Cohen D, Dicicco-Bloom B, Miller WL, Stange KC, Crabtree BF. Understanding healing relationships in primary care. Ann Fam Med 2008; 6:315-22.

46. Starfield B, Shi L. Primary care impact on health outcomes: a literature review. Milbank Q. In press.

47. Kerr S. On the folly of rewarding A, while hoping for B. Acad Manage J 1975;18:769-83.

48. Petersen LA, Woodard LD, Urech T, Daw C, Sookanan S. Does pay-for-performance improve the quality of health care? Ann Intern Med 2006;145: 265-72. 